\title{
Birth Weight in Relation to Maternal Blood Levels of Selected Elements in Slovenian Populations: A Cross-sectional Study
}

\author{
Marta Jagodic ${ }^{1,2}$, Janja Snoj Tratnik ${ }^{1,2}$, Darja Mazej ${ }^{1}$, Anja Stajnko ${ }^{1,2}$, Majda Pavlin ${ }^{1,2}$, Mladen Krsnik ${ }^{3}$, Alfred B. \\ Kobal $^{4}$, Lijana Kononenko ${ }^{5}$, Jon Øyvind Odland ${ }^{6}$ and Milena Horvat ${ }^{1,2}$ \\ 1. Jožef Stefan Institute, Jamova Cesta 39, 1000 Ljubljana, Slovenia \\ 2. Jožef Stefan' International Postgraduate School, Jamova Cesta 39, 1000 Ljubljana, Slovenia \\ 3. Institute of Clinical Chemistry and Biochemistry, University Medical Centre Ljubljana, Njegoševa 4, 1000 Ljubljana, Slovenia \\ 4. Ex-Department of Occupational Health, Idrija Mercury Mine, Arkova 43, 5280 Idrija, Slovenia \\ 5. Ministry of Health, Chemicals Office of the Republic of Slovenia, Ajdovščina 4, 1000 Ljubljana, Slovenia \\ 6. Department of Community Medicine, Faculty of Health Sciences, UIT The Arctic University of Norway, Hansine Hansens veg 18, \\ 9019 Tromsø, Norway
}

\begin{abstract}
The objective of the present study was to evaluate the relation between maternal blood levels of selected toxic and potentially toxic elements (manganese $(\mathrm{Mn})$, copper $(\mathrm{Cu})$, zinc $(\mathrm{Zn})$, arsenic (As), selenium (Se), cadmium $(\mathrm{Cd})$, lead $(\mathrm{Pb})$ and mercury $(\mathrm{Hg})$ ) and birth weight of their new-borns in a Slovenian population, taking into account maternal socio-demographic characteristics and dietary habits. 535 women from 12 regions of Slovenia were recruited at delivery. Maternal blood was collected at 1.5 months after birth. Associations between birth weight and a) predictors obtained through the questionnaires and b) levels of selected elements were tested using bivariate tests and multiple linear regression. Multiple regression models revealed maternal age as an additional predictor for birth weight and confirmed pre-pregnancy body mass, estimated gestational age and gender of the baby as the main predictors for birth weight. Mn in maternal blood was significantly and positively associated with birth weight. The positive association observed between birth weight and $\mathrm{Mn}$ in maternal blood could be explained by the essentiality of $\mathrm{Mn}$ in foetal development as an important cofactor in enzyme reactions in bone formation and in metabolic regulation for amino acid, lipid, protein and carbohydrate levels.
\end{abstract}

Key words: Birth weight, toxic elements, essential elements, maternal whole blood, preventive health, Slovenia.

\section{Introduction}

Concern over problems from exposure to environmental influences on health impairment of the new-born child requires continuous monitoring of the exposure of a population to environmental agents [1]. In response, many developed countries and international bodies have established large-scale human biomonitoring surveys (HBM) [2], which show the concentrations of chemicals and their metabolites

Corresponding author: Milena Horvat, Ph.D., professor, research fields: environmental health, biogeochemistry, human biomonitoring. in body tissues including, for example, blood, serum, urine, and breast milk. The levels of environmental chemicals in a person's body fluid and/or tissue are indicative of exposure, but not necessarily the cause of a disease or an adverse effect [3, 4].

In this study, some of the most relevant toxic and potentially toxic elements, listed among the 20 top chemicals on the Priority list of Hazardous Substances [5], were addressed. Among the most susceptible groups are pregnant women and children, the latter because of their increased exposure to mixtures of chemicals, increased absorption rates and a diminished ability to detoxify many exogenous compounds, all 
relative to those of adults [6]. The developing foetus is particularly susceptible due to partial lack of the blood-brain barrier [7] and to the rapid and tightly controlled growth of the brain during the pregnancy period [6]. The potential risk to the developing foetus is reflected in the level of contaminants in the maternal blood. It is known that several of these substances are passed from mother to foetus through the umbilical cord and later on to the child through breast milk $[8,9]$. Of concern are the long-term, subtle effects that could influence reproductive health, pregnancy outcomes (e.g., birth weight, length, gestational age), reduced resistance against diseases, mental development of the child, or the increased risk of cancer [10]. The toxicity, metabolism and absorption of certain elements are dependent mainly on the chemical species and/or oxidation state. For example, dietary exposure to organic arsenic is unlikely to cause a health risk, but inorganic arsenic is recognized as genotoxic and is a known human carcinogen [11].

Essential elements also have a potential for toxicity and risk assessments for their essential versus toxic effects have been carried out $[12,13]$. Trace element deficiencies have been reported in about $40 \%$ of the world's population, mostly from developing countries. This is probably a result of poor diet and can lead to endocrine, cardiovascular, skeletal, liver, gastrointestinal, kidney, genetic, and ophthalmologic disorders [14]. Furthermore, effects of toxic elements depend on the interaction between toxic and essential elements, especially when the metabolism of a toxic element is similar to that of an essential element. Exposure to toxic elements is also influenced by lifestyle factors [15].

Birth weight is the main factor influencing infant mortality rates, health of babies and a healthy later life. Birth weight is associated with the gender of the baby, the anthropometry of the mother (e.g., poor pre-pregnancy weight, weight gain during pregnancy, shorter gestational age), parity, multiple birth, complicated pregnancy (e.g., maternal anaemia, pregnancy diabetes, poor antenatal care, problems with placenta, maternal infections), restricted foetal growth, poor nutritional intake of women, and deprived socio-economic conditions [10, 16-19]. Effects are also associated with physically demanding work during pregnancy, environmental tobacco smoke, intensity and duration of cigarette smoking during pregnancy, taking illicit drugs and consuming alcohol [10, 16-20]. In addition, maternal health in relation to pregnancy, the mother's genetic background, age, location of residence and education also influence birth weight [17, $18]$.

Various associations between trace elements and birth weight have been observed. Studies have shown significant direct correlations between birth weight and maternal levels of zinc $(\mathrm{Zn})$ and copper $(\mathrm{Cu})$ in serum [21]. As for manganese ( $\mathrm{Mn})$, it has been suggested that Mn levels in maternal whole blood influence birth weight $[22,23]$, while the absence of a correlation between birth weight and $\mathrm{Mn}, \mathrm{Cu}, \mathrm{Zn}$ and selenium (Se) in maternal blood has also been reported [24-26]. Levels of $\mathrm{Mn}$ in maternal blood have been found to increase throughout pregnancy [27,28], while lower or higher Mn concentrations in maternal blood has been associated with low birth weight (U-shaped relationship) [29, 30]. Toxic elements (cadmium (Cd), lead $(\mathrm{Pb})$, arsenic (As) and mercury $(\mathrm{Hg}))$ may have negative effect on birth weight at relatively low levels of exposure. Xu et al. suggested that the presence of As in maternal blood has a negative influence on birth weight and on gestational age in boys [31]. Studies investigating the effects of $\mathrm{Cd}$ exposure during pregnancy have been in conclusive: some studies [32-34] report negative associations, some positive [35], and others no association at all [36, 37]. Exposure to $\mathrm{Pb}$ was found to be associated with birth weight either negatively [37, 38], or insignificantly [34-36]. Non-significant correlations have been observed for $\mathrm{Hg}$ in maternal blood [35, 36, 39].

The National HBM program was implemented in Slovenia, according to the Chemicals Act in 2003 and 
performed in the period from 2007 to 2014 for the first time to estimate the exposure of inhabitants of different are as to selected environmental chemicals and to provide data for an environmental health risk assessment [40]. Attention was on exposure to essential and toxic substances during pregnancy and the breastfeeding period, since these are recognized as being potentially responsible for adverse development and health in children. The main objective of the present study was to examine the relation between birth weight and maternal blood levels of toxic and potentially toxic elements determined within the Slovenian HBM program and taking into account the socio-demographic characteristics and diet of the mothers.

\section{Materials and Methods}

\subsection{Description of Study Population}

The study populations included first-time mothers who gave birth to a living baby from 12 different areas across Slovenia, including three urban areas (140 women), three rural areas (109 women) and six potentially contaminated areas due to past industrial activity (245 women) (Fig. 1). Areas of Jesenice, Celje, Idrija with Posočje, Savinjsko-posavska and Zasavje are known to be contaminated with metals, while the area of Bela krajina with polychlorinated biphenyls (PCBs).

\subsection{Recruitment and Sampling}

The mothers were recruited between 2007 and 2014 through selected maternity hospitals, parenting schools and gynaecologists. Maternal blood, urine, hair and milk samples were collected between 1 to 3 months after delivery. Questionnaires were given to the mothers to obtain information about their lifestyle, living environment, socio-economic status, nutritional habits (frequency of intake), health status of the mother-child pair and breastfeeding status. A total of 535 women signed informed consent, however, 41 women were excluded due to missing blood samples, gestational diabetes, diabetes type I and II, delivery of twins, lifestyle or occupational exposure and missing information on birth weight. The final database contains data from 494 women.

\subsection{Sample Preparation and Chemical Analysis of Whole Blood}

Venous blood samples were collected using vacutainer tubes containing $\mathrm{K}_{2}$ EDTA (BD Vacutainer ${ }^{\circledR}$ Blood Collection Tubes for Trace Element Testing, Becton Dickinson, US), following regular laboratory procedures,

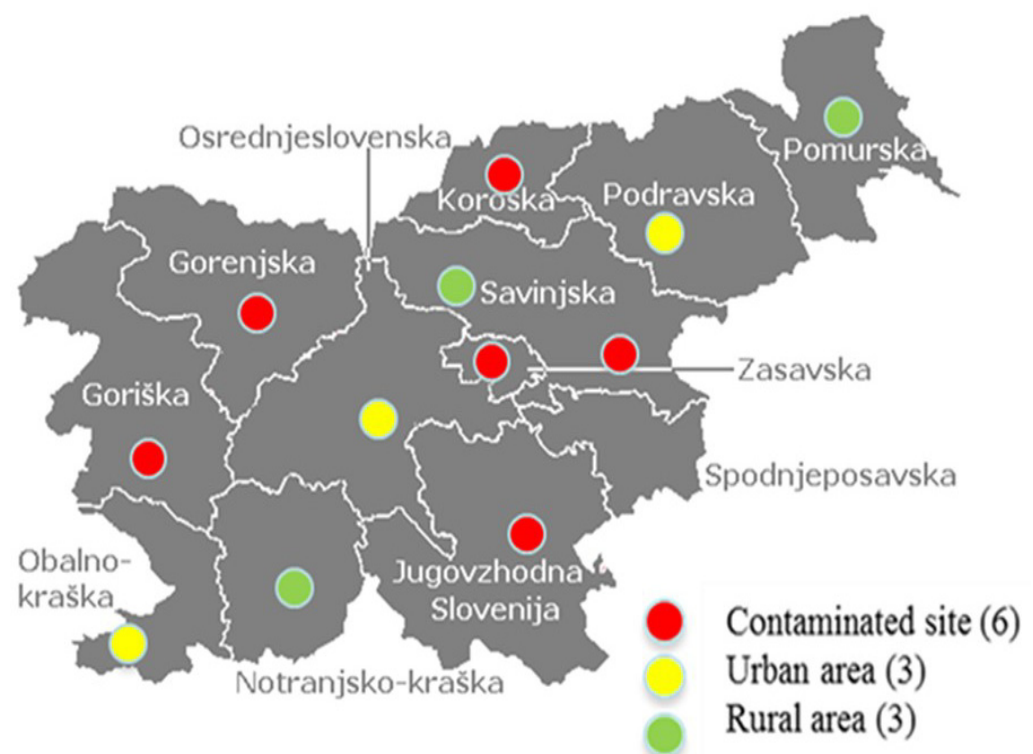

Fig. 1 Sampling locations in Slovenia [40]. 
and stored at $-20{ }^{\circ} \mathrm{C}$ until analysis. Selected toxic and potentially toxic elements in the maternal whole blood samples were analysed at the Jožef Stefan Institute, Slovenia.

Whole blood sample is generally recognized as an appropriate matrix for assessment of exposure to $\mathrm{Mn}$, $\mathrm{Se}, \mathrm{Cu}, \mathrm{As}, \mathrm{Cd}, \mathrm{Pb}$ and $\mathrm{Hg}$. However, in the case of $\mathrm{Zn}$ and $\mathrm{Cu}$, serum is a more indicative matrix for their status in the body [41]. Due to cost effectiveness and the limited blood volume available from the mothers, elements were determined in whole blood. For the same reason sample size varied for some elements on account of an insufficient amount of sample and this is the reason why Mn was not determined in participants from three of the selected study areas (pilot phase including one urban, one rural and one potentially contaminated area). To allow comparability with other studies, all values have been converted to $\mathrm{ng} / \mathrm{mL}$, using a factor of $1.053 \mathrm{~g} / \mathrm{mL}$ for women [42].

2.3.1 Determination of $\mathrm{As}, \mathrm{Cd}, \mathrm{Cu}, \mathrm{Mn}, \mathrm{Pb}, \mathrm{Se}$ and $\mathrm{Zn}$ in Whole Blood

$\mathrm{As}, \mathrm{Cd}, \mathrm{Cu}, \mathrm{Mn}, \mathrm{Pb}, \mathrm{Se}$ and $\mathrm{Zn}$ in whole blood were analysed using an Octapole Reaction System (ORS) Inductively Coupled Plasma Mass Spectrometer (ICP-MS, 7500 ce, Agilent, Tokyo, Japan) equipped with an ASX-510 Autosampler (Cetac), a Babington nebuliser and a Scott-type spray chamber. The ORS was operated in helium gas mode to avoid interference.

Aliquots of $0.3 \mathrm{~mL}$ of whole blood sample werediluted ten times with an alkaline solution containing Triton X-100 and disodium ethylene diamine tetraacetic acid (EDTA) in contamination free tubes [43]. An aliquot of an internal standard solution containing Scandium (Sc), Gallium (Ga), Yttrium (Y) and Gadolinium $(\mathrm{Gd})$ was added to each tube and standard addition was used for calibration. The following isotopes were monitored ${ }^{45} \mathrm{Sc},{ }^{55} \mathrm{Mn},{ }^{63} \mathrm{Cu}$, ${ }^{66} \mathrm{Zn},{ }^{69} \mathrm{Ga},{ }^{75} \mathrm{As},{ }^{78} \mathrm{Se},{ }^{89} \mathrm{Y},{ }^{111} \mathrm{Cd},{ }^{114} \mathrm{Cd},{ }^{157} \mathrm{Gd},{ }^{206} \mathrm{~Pb}$, ${ }^{207} \mathrm{~Pb},{ }^{208} \mathrm{~Pb}$. The instrument was tuned daily using a solution containing $\mathrm{Li}, \mathrm{Mg}, \mathrm{Y}, \mathrm{Ce}, \mathrm{Tl}$ and $\mathrm{Co}$. On all isotopes were quantified using one central point of the spectral peaks and three repetitions.

Analytical precision was 5\%, for $\mathrm{Pb}, \mathrm{Mn}, \mathrm{Cu}, \mathrm{Zn}$ and Se, $10 \%$ for As and $20 \%$ for $\mathrm{Cd}$. Limits of detection (LOD), calculated as three times the standard deviations of the blank sample, were $0.2,0.4,0.1,8,7$, 30, $0.4 \mathrm{ng} / \mathrm{mL}$ for $\mathrm{Cd}, \mathrm{Pb}, \mathrm{As}, \mathrm{Se}, \mathrm{Cu}, \mathrm{Zn}$ and $\mathrm{Mn}$, respectively. The accuracy of the results was checked against the certified material Seronorm Trace Elements Whole Blood L-1 (SERO AS, Norway).

\subsubsection{Determination of Total Hg in Whole Blood}

The concentration of total $\mathrm{Hg}$ in whole blood was determined using a Direct Mercury Analyser (DMA-80, Milestone Srl, Italy). A known amount of blood (0.1-0.2 mL) was weighed out into a quartz boat. The sample was first dried and then thermally and chemically decomposed at $650{ }^{\circ} \mathrm{C}$. An oxygen stream then transfers the decomposition products through an amalgamator that selectively traps gaseous mercury, which is subsequently desorbed for quantification. The resulting mercury vapour was analysed using atomic absorption spectrophotometry at $254 \mathrm{~nm}$ [44].

The analytical precision was $5 \%$ and with a LOD of $0.2 \mathrm{ng} / \mathrm{mL}$. The reference material, Seronorm Trace Elements Whole Blood L-1 (SERO AS, Norway), was used to check the accuracy of the results.

\subsection{Statistical Analysis}

Statistical analysis included descriptive statistics (means, minimum ( $\min$ ), maximum ( $\max$ ), geometric means (GM), confidential intervals (CI) of GM, and percentage), bivariate analysis (Spearman for categorical data and Pearson for continuous), analysis of between-group effects (Mann-Whitney $U$, Kruskall-Wallis test or ANOVA) and multiple linear regression. Non-normally distributed data (concentrations of elements, baby birth length) were $\log 10$-transformed. Concentrations of elements below the LOD were assigned arbitrarily the value of $1 / 2$ LOD. Multiple linear regression (using the enter all method) was used to evaluate the association between birth weight and all covariates that correlate with the 
dependant variable with a level of significance $P<$ 0.25 . Highly correlated variables were not included in the same model to avoid the effect of multi-collinearity. Predefined confounders were fixed into the models (age of mother, education, pre-pregnancy body mass index (BMI) and residence). $P$-values $<0.05$ were considered significant. All statistical analyses were performed using IBM SPSS Statistic Version 23 and STATA/SE 12.1 .

\section{Results and Discussion}

Table 1 gives the characteristics of the study population. The mean age of the mothers was 29 years, the mean pre-pregnancy BMI was $23.1 \mathrm{~kg} / \mathrm{m}^{2}$, the mean estimated gestational length was 39.7 weeks, 50\% of women have at least university education, $53.8 \%$ of babies were males, and the mean birth length for all babies was $51.4 \mathrm{~cm}$. The mean birth weight of the babies in our study was comparable with those reported elsewhere [23, 30, 35, 38, 45, 46]. A total of $3.4 \%$ of the new-borns were below the criterion for "low birth weight" of 2,500 g [17], and $0.2 \%$ of new-borns were below 1,500 g, considered as a "very low birth weight" [47]. "High birth weights" (> 4,000 g) [48] were reported for $8.3 \%$ of the new-borns.

Table 2 gives the geometric mean concentrations of selected elements in maternal whole blood samples. In general, the level of exposure to toxic elements was low and did not pose a health risk for either the mothers or their babies (Table 2). The percentage of individuals having blood concentrations of $\mathrm{Hg}, \mathrm{Pb}$ and $\mathrm{Cd}$ above the established reference values were $0.81,0.40$, and $3.64 \%$, respectively (Table 2) [49, 51-53]. The GM of $\mathrm{Cd}$ in non-smokers was $0.34 \mathrm{ng} / \mathrm{mL}, 0.41 \mathrm{ng} / \mathrm{mL}$ in pre-pregnancy smokers $(12 \%)$ and $0.63 \mathrm{ng} / \mathrm{mL}$ in pregnancy smokers (1.2\%). As observed from correlations between blood levels and questionnaire variables, $\mathrm{Hg}$ was significantly associated with consumption of fresh sea fish $\left(\mathrm{r}_{\mathrm{s}}=0.269, P<0.001\right)$ and canned sea fish $\left(\mathrm{r}_{\mathrm{s}}=0.237, P<0.001\right)$ (data not shown), hence the weak correlations. Furthermore, no relationship was observed between $\mathrm{Hg}$ and amalgam fillings $\left(\mathrm{r}_{\mathrm{s}}=0.017, P=0.739\right)$. Based on the questionnaire data, $41.1 \%$ of women reported eating fresh seafood at least once per month (on average less than once per month); $17.2 \%$ of mothers reported having noamalgam fillings and $23.3 \%$ did not answer this question. On average women had 4.36 amalgam fillings (data not shown).

In the case of $\mathrm{Cu}, \mathrm{Zn}$ and $\mathrm{Se}, 2.0,0.2$ and $0.4 \%$ of individuals exhibited levels below their lower reference values, while $3.2,1.4$ and $4.9 \%$ of individuals had levels of $\mathrm{Mn}, \mathrm{Cu}, \mathrm{Zn}$ and $\mathrm{Se}$ above the upper references levels. In contrast, $75.7 \%$ of women exceeded the reference levels for Mn [49-51]. The relatively high levels of $\mathrm{Mn}$ in the study population were similar to those previously reported in postpartum mothers form Norway [28], in mothers before delivery in South

Table 1 General characteristics of the Slovenian study population.

\begin{tabular}{lllll}
\hline Characteristics of study population & N & Mean (min-max) & \% of participants \\
\hline \multirow{6}{*}{ Women } & Age at delivery (years) & 493 & $29.0(19-39)$ & \\
& Pre-pregnancy body mass index $\mathbf{( k g / \mathbf { m } ^ { 2 } )}$ & 483 & $23.1(16.6-44.8)$ & \\
& Estimated gestational length (weeks) & 473 & $39.7(28-42)$ & 7.4 \\
& Education: primary & & & 42.6 \\
& secondary & 35 & & 50.0 \\
\hline \multirow{5}{*}{ Childrensity } & 200 & & 53.8 \\
& Gender: male & 235 & & 46.2 \\
& female & 266 & & \\
\hline
\end{tabular}

$\mathrm{N}=$ number of samples, $\min =$ minimum level, $\max =$ maximum level. 
Table 2 Concentrations of elements $(\mathrm{ng} / \mathrm{mL})$ in maternal whole blood of the study population and respective reference values.

\begin{tabular}{llllllll}
\hline Elements & $\mathbf{N}$ & $\mathbf{G M}$ & $\mathbf{9 5 \%} \mathbf{C I}$ of GM & $\begin{array}{l}\text { Range } \\
\text { (min-max) }\end{array}$ & $\begin{array}{l}\text { Reference } \\
\text { value/range }\end{array}$ & $\begin{array}{l}\text { \% below } \\
\text { reference } \\
\text { value }\end{array}$ & $\begin{array}{l}\text { \% above } \\
\text { reference } \\
\text { value }\end{array}$ \\
\hline $\mathbf{M n}(\mathbf{n g} / \mathbf{m L})$ & 370 & $\mathbf{1 7 . 2}$ & $16.7-17.8$ & $5.8-35.2$ & $\mathbf{4 - 1 4}[27]$ & 0.00 & 75.7 \\
$\mathbf{C u}(\mathbf{n g} / \mathbf{m L})$ & 494 & $\mathbf{1 , 0 7 7}$ & $1,057-1,084$ & $657-2,004$ & $\mathbf{8 0 0 - 1 , 4 0 0}[51]$ & 2.02 & 3.24 \\
$\mathbf{Z n}(\mathbf{n g} / \mathbf{m L})$ & 494 & $\mathbf{6 , 7 3 1}$ & $6,644-6,819$ & $3,010-11,733$ & $\mathbf{3 , 5 0 0 - 9 , 1 0 0}[50]$ & 0.20 & 1.42 \\
$\mathbf{A s}(\mathbf{n g} / \mathbf{m L})$ & 494 & $\mathbf{0 . 9 2 9}$ & $0.866-0.997$ & $0.201-16.798$ & $<\mathbf{2 0}[51]$ & - & 0.00 \\
$\mathbf{S e}(\mathbf{n g} / \mathbf{m L})$ & 494 & $\mathbf{9 4 . 7}$ & $93.2-96.3$ & $53.9-175.9$ & $\mathbf{6 0 - 1 3 0}[49]$ & 0.40 & 4.86 \\
$\mathbf{C d}(\mathbf{n g} / \mathbf{m L})$ & 493 & $\mathbf{0 . 3 4 6}$ & $0.328-0.365$ & $0.20-3.084$ & $<\mathbf{1 . 0}[53]$ & - & 3.64 \\
$\mathbf{P b}(\mathbf{n g} / \mathbf{m L})$ & 494 & $\mathbf{1 6 . 8}$ & $16.2-17.4$ & $4.2-71.9$ & $<\mathbf{7 0}[53]$ & - & 0.40 \\
$\mathbf{H g}(\mathbf{n g} / \mathbf{m L})$ & 493 & $\mathbf{1 . 1 1}$ & $1.03-1.19$ & $0.20-10.17$ & $<\mathbf{5 . 8}[55]$ & - & 0.81 \\
\hline
\end{tabular}

$\mathrm{CI}=$ confidence interval, $\mathrm{GM}=$ geometric mean, $\min =$ minimum level, $\max =$ maximum level, $\mathrm{N}=$ number of samples.

Table 3 Correlation between birth weight and selected variables.

\begin{tabular}{llll}
\hline Correlations with baby birth weight (kg) & & & \\
\hline Variable & $\mathbf{r}_{\mathbf{s}}$ & $\boldsymbol{P}$-value & $\mathbf{N}$ \\
\hline Residential location* & - & 0.140 & 448 \\
Age of mother (years)-groups & -0.043 & 0.346 & 493 \\
Pre-pregnancy body mass index-groups & 0.092 & 0.042 & 483 \\
Education-groups & -0.033 & 0.469 & 470 \\
Estimated gestational age (week)-groups & 0.325 & 0.000 & 473 \\
Gender of baby & - & 0.033 & $\mathbf{N}$ \\
\hline & $\mathbf{r}_{\mathbf{p}}$ & $\boldsymbol{P}$-value & 370 \\
Log10 Mn (ng/mL) & 0.178 & 0.001 & 494 \\
Log10 Cu (ng/mL) & -0.074 & 0.102 & 494 \\
Log10 Zn (ng/mL) & 0.004 & 0.938 & 494 \\
Log10 As (ng/mL) & 0.018 & 0.689 & 494 \\
Log10 Se (ng/mL) & -0.042 & 0.347 & 493 \\
Log10 Cd (ng/mL) & 0.053 & 0.239 & 494 \\
Log10 Pb (ng/mL) & 0.076 & 0.091 & 493 \\
Log10 Hg (ng/mL) & -0.040 & 0.376 & 493 \\
Baby length (cm) & 0.717 & 0.000 & \\
\hline
\end{tabular}

*potentially contaminated, rural, and urban. GM = geometric mean, $P$-value shows the level of significance, $\mathrm{N}=$ number of samples.

African coastal communities (from part "Rural 2") [54], in pregnant woman from Southwest Quebec [46], in the Mother and Children's Environmental Health birth cohort study in Seoul, in Cheonan, and Ulsan in the Republic of Korea at delivery [30] and in pregnant women from Costa Rica [25]. The concentrations of essential elements at 6 weeks postpartum may have changed according to physiological and metabolic changes during pregnancy and during the postpartum/lactation period, as was demonstrated by Hansen et al. who found that concentrations of Mn, Se, $\mathrm{Zn}$ and As increased postpartum [28].

Of the variables tested, pre-pregnancy BMI, estimated gestational age, gender of the baby and baby length were associated significantly with birth weight (Table 3). Among the selected elements, significant correlations were observed between the birth weight and $\mathrm{Mn}$ levels, and marginally significant correlations between $\mathrm{Pb}$ and $\mathrm{Cu}$ levels in the maternal blood samples (Table 3). No statistically significant correlations were observed between birth weight and consumption of different food items.

A positive association between $\mathrm{Mn}$ in maternal blood and birth weight was confirmed by the linear regression model, in which the Mn levels were adjusted for the relevant predictors (Table 4). Among 
Table 4 Multiple linear regression between birth weight and selected variables.

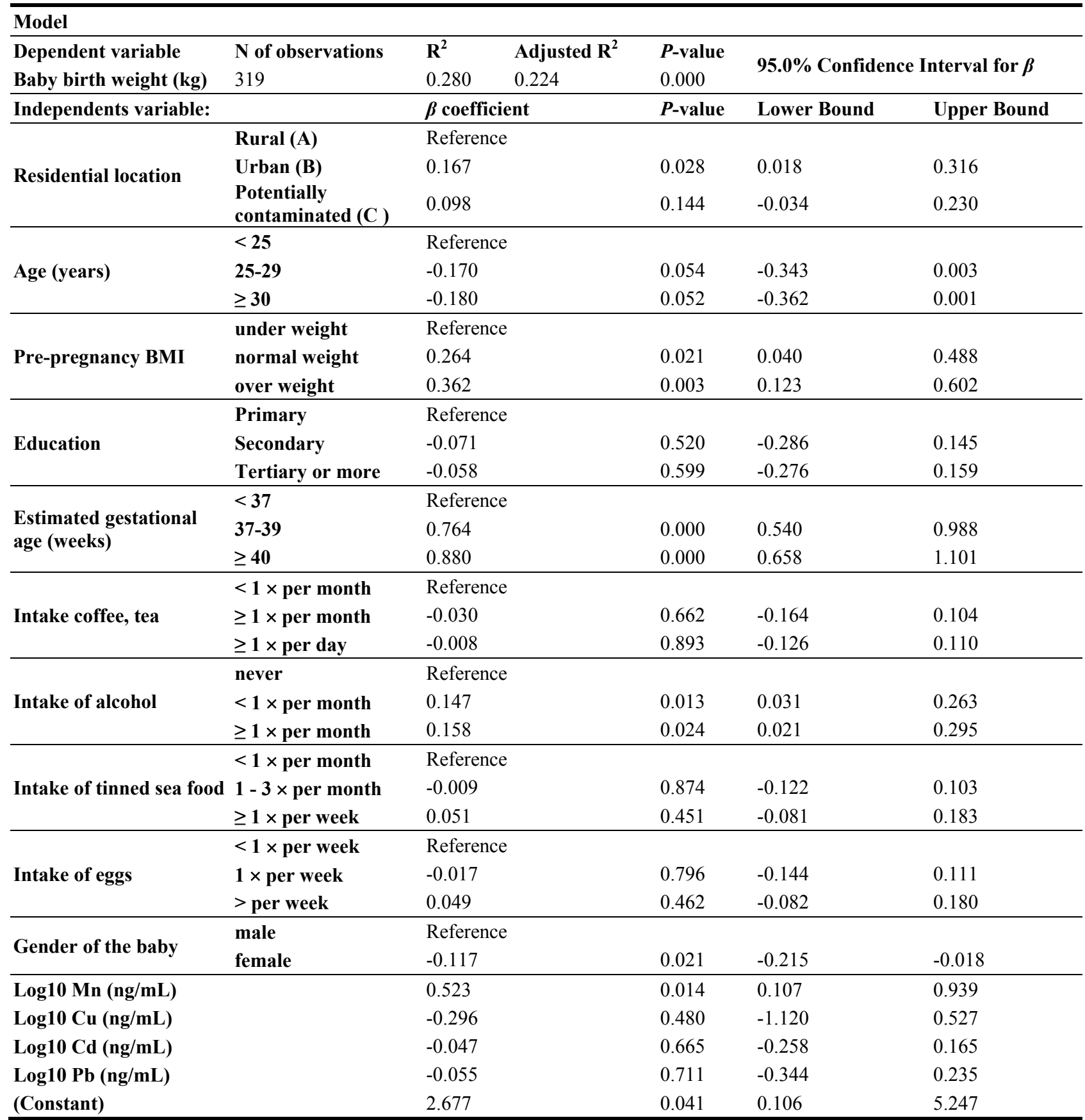

$\mathrm{N}=$ number of samples, $P$-value shows the level of significance, $\mathrm{R}^{2}=\mathrm{R}$ Square $=$ gradient of the regression line and the strength of the relationship between a predictor and the outcome; $\beta$ coefficient $=$ gradient of the regression line and the strength of the relationship between a predictor and the outcome, $\mathrm{BMI}=$ body mass index.

the predictors tested, the regression model revealed statistically significant correlations between birth weight and pre-pregnancy BMI, intake of alcohol before pregnancy, the baby's gender, as well as a marginally significant correlation between birth weight and the age of the mother. A higher pre-pregnancy BMI was associated with a higher birth weight, which agrees with the findings of other studies $[16,17,56]$. Furthermore, the differences in gender-related birth weight (boys were heavier) is also in accordance with 
an earlier report [17]. Teenagers and young women have been reported to have lighter babies [17, 18], but in the present study the opposite was observed. The reason for this could be the narrower age interval (19-39 years) included in the present study. The model also shows that babies from urban areas had higher birth weights than those from rural areas (Table 4).

The positive association observed between birth weight and $\mathrm{Mn}$ in maternal blood could be explained by the essential role of $\mathrm{Mn}$ in foetal development. $\mathrm{Mn}$ is an important cofactor in enzyme reactions in bone formation and in metabolic regulation of levels of amino acid, lipid, protein and carbohydrate [25, 27]. However, in contrast to the present study, only non-significant or non-linear correlations between birth weight and Mn have been reported [22, 23, 25, 26].

In contrast with the literature [20], non-significant correlations between maternal smoking and birth weight were observed in the present study, probably due to the low frequency of smoking among the participating mothers (1.2\% of women smoked during pregnancy and $12.4 \%$ before pregnancy). Although it is known that some food items appear to be beneficial for an appropriate birth weight $[57,58]$, our study failed to reveal any significant associations between birth weight and the food items that were included in the study questionnaire. The only association was between birth weight and alcohol intake before the pregnancy, but it was positive and also questionable due to the low levels of alcohol intake in the study population (average consumption was less than once per month).

\section{Limitations}

A disadvantage of the Slovenian study presented here is that the gestational age was estimated from the information obtained from the mothers, i.e., the estimated gestational age was calculated from the date of birth and predicted date of birth reported by the mothers, since clinical information from the maternity hospitals was not available. Another limitation of the study is the time-period in which blood samples were collected (1.5 months postpartum). Since literature data suggest that food intake during pregnancy can affect the levels of elements in maternal blood during and after pregnancy [59], the levels of selected elements in postpartum maternal blood samples could be used for estimation of pregnancy exposures.

\section{Conclusions}

The present study is the first of its kind to examine exposure to such a wide range of trace elements in relation to infant birth weight while taking into account the socio-demographic characteristics and dietary habits of the mothers. Exposure to toxic elements was low and comparable to that in other populations. Most mothers did not exceed the given reference levels. The birth weight was in agreement with other literature studies. The results of this study also show that maternal age, pre-pregnancy BMI, estimated gestational age, length of baby and marginally the gender of baby all influence the birth weight. Despite low, environmentally relevant, exposure to the selected potentially toxic elements, a significant and positive correlation was observed between birth weight and the levels $\mathrm{Mn}$ in blood from Slovenian mothers. Additional evaluations and further studies are needed to focus on this specific and other potential associations.

\section{List of Abbreviations}

AMAP: Arctic Monitoring and Assessment Program; ANOVA: Analysis of variance; As: Arsenic; ATSDR: Agency for Toxic Substances and Disease Registry; BMI: Body mass index; Cd: Cadmium; CDC: Centres for Disease Control and Prevention; $\mathrm{Cu}$ : Copper; LOD: Limit of detection; DMA: Direct Mercury Analyser; EDTA: Ethylenediaminetetraacetic acid; Ga: Gallium; Gd: Gadolinium; GM: Geometric mean; HBM: Human biomonitoring study; $\mathrm{Hg}$ : Mercury; ICP-MS: Inductively Coupled Plasma Mass Spectrometer; K: Potassium; max: Maximum level; min: Minimum level; Mn: Manganese; N: number of samples; NMEC: 
National Medical Ethics Committee; ORS: Octapole Reaction System; $P$ : $P$-value shows the level of significance; $\mathrm{Pb}$ : Lead; PCBs: Polychlorinated biphenyls; $\mathrm{R}^{2}$ : R Square $=$ gradient of the regression line and the strength of the relationship between a predictor and the outcome; $r_{\mathrm{p}}$ : Pearson's correlation coefficient; $r_{\mathrm{s}}$ : Spearman's correlation coefficient; Sc: Scandium; Se: Selenium; WHO: World Health Organization; Y: Yttrium; Zn: Zinc; $\boldsymbol{\beta}$ : $\boldsymbol{\beta}$ coefficient $=$ gradient of the regression line and the strength of the relationship between a predictor and the outcome.

\section{Declarations}

\subsection{Ethics Approval and Consent to Participate}

All procedures performed in this study involving human participants were in accordance with the ethical standards of the institutional and/or national research committee and with the 1964 Helsinki declaration and its later amendments or comparable ethical standards. The human biomonitoring study was approved by the Republic of Slovenia National Medical Ethics Committee (NMEC) with numbers of accordance 42/12/07 and 53/07/09. Participation of women was voluntary; informed consent was obtained from all individual participants included in the study. All samples and related information were coded and anonymised. The participants had the right to withdraw from the study at all stages of the study period.

\subsection{Consent for Publication}

Not applicable.

\subsection{Availability of Data and Materials}

The dataset used in this article was obtained from the National Human Biomonitoring Program in Slovenia. The complete dataset has not yet been published but is expected to be available within five years.

\subsection{Competing Interests}

The authors declare that they have no competing interests.

\subsection{Funding}

This work was supported by the National Human Biomonitoring program financed by the Chemicals Office of the Republic of Slovenia and the Slovenian Research Agency and also by Arctic Monitoring and Assessment Program (AMAP); the Department of Community Medicine, Faculty of Health Sciences, UiT the Arctic University of Norway, Tromsø; Stavanger University Hospital and Stavanger Helseforsking AS, Stavanger and Jožef Stefan International Postgraduate School (IPS) and "Cross-Mediterranean Environment and Health Network" (CROME-LIFE+ project).

\subsection{Authors' Contributions}

MJ and DM measured concentrations of selected elements in maternal blood samples by ICP-MS. MP, AS, JST and MJ carried out measurements of total mercury in maternal blood samples. MJ performed the statistical analysis. MJ, JST, DM, MH, ABK, LK, MK and JØO conceived the study, and participated in its design and coordination as well as helping to draft the manuscript. All authors read and approved the final manuscript.

\section{Acknowledgments}

This work was supported by the National Human Biomonitoring program financed by the Chemicals Office of the Republic of Slovenia and the Slovenian Research Agency and also by Arctic Monitoring and Assessment Program (AMAP); the Department of Community Medicine, Faculty of Health Sciences, UiT the Arctic University of Norway, Tromsø; Stavanger University Hospital and Stavanger Helseforsking AS, Stavanger and Jožef Stefan International Postgraduate School (IPS) and "Cross-Mediterranean Environment and Health Network" (CROME-LIFE+ project). We thank members of the ARCRISK/EMASAR research group. A special acknowledgment is given to Inger Økland, Jørn Schulz and Solrunn Hansen for contributions in design and statistical assessment of the study. We 
thank mothers for donating their biological samples and for their participation in the study.

\section{References}

[1] Kundsen, L. E., Hundebøll, N., and Merlo, D. F. 2012. "Introduction to Human Biomonitoring." In L. E. Knudsen and D. F. Merlo (Eds.), Biomarkers and Human Biomonitoring, Volume 1: Ongoing Programs and Exposures-Issues in Toxicology 9 (1): 1-15. Royal Society of Chemistry.

[2] Pino, A., Amato, A., Alimonti, A., Mattei, D., and Bocca, B. 2012. "Human biomonitoring for metals in Italian urban adolescents: data from Latium Region." International journal of hygiene and environmental health 215 (2): 185-90.

[3] CDC. 2009. "Fourth National Report on Human Exposure to Environmental Chemicals (USA)." CDC-Department of Health and Human Services and Centers for Disease Control and Prevention.

[4] CDC. 2013. Fourth National Report on Human Exposure to Environmental Chemicals-Updated Tables, September 2013.

[5] ATSDR, The Priority List of Hazardous Substances, 2013. http://www.atsdr.cdc.gov/spl/(accessed February 9, 2015).

[6] Grandjean, P., and Landrigan, P. J. 2006. "Developmental neurotoxicity of industrial chemicals." Lancet 368 (9553): 2167-78.

[7] Andersen, H. R., Nielsen, J. B., and Grandjean, P. 2000. "Toxicologic evidence of developmental neurotoxicity of environmental chemicals.” Toxicology 144 (1-3): 121-7.

[8] Röllin, H. B., Rudge, C. V. C., Thomassen, Y., Mathee, A., and Odland, J. Ø. 2009. "Levels of toxic and essential metals in maternal and umbilical cord blood from selected areas of South Africa--results of a pilot study." Journal of environmental monitoring: JEM 11 (3): 618-27.

[9] Rudge, C. V, Röllin, H. B., Nogueira, C. M., Thomassen, Y., Rudge, M. C., and Odland, J. Ø. 2009. "The placenta as a barrier for toxic and essential elements in paired maternal and cord blood samples of South African delivering women." Journal of environmental monitoring: JEM 11 (7): 1322-30.

[10] Stillerman, K. P., Mattison, D. R., Giudice, L. C., and Woodruff, T. J. 2008. "Environmental Exposures and Adverse Pregnancy Outcomes: A Review of the Science." Reproductive Sciences 15 (7): 631-50.

[11] Nordberg, G. F., Fowler, B. A., Nordberg, M., and Friberg, L. T. (Eds.). 2007. Handbook on the Toxicology of Metals.

[12] Burtis, C., Ashwood, E., and Bruns, D. (Eds.) 2012. Textbook of Clinical Chemistry and Molecular Diagnostics (5th ed.). Missouri: Saunders.

[13] Chellan, P., and Sadler, P. J. 2015. "The elements of life and medicines." Philosophical transactions. Series A, Mathematical, physical, and engineering sciences 373 (2037).

[14] Nriagu, J. O., and Szefer, P. (Eds.) 2007. Mineral Components in Foods.

[15] Burtis, C., Ashwood, E., and Bruns, D. (Eds.) 1999. Textbook of Clinical Chemistry and Molecular Diagnostics (3rd ed.). Pennsylvania: Saunders.

[16] WHO. 1992. "Low birth weight-WHO Report".

[17] UNICEF, and WHO. 2004. Low Birthweight: Country, regional and global estimates. Unicef.

[18] Anjum, F., Javed, T., Afzal, M. F., and Sheikh, G. A. 2011. "Maternal risk factors associated with low birth weight: A Case Control Study." Annals 17 (3): 223-8.

[19] Muthayya, S. 2009. "Maternal nutrition and low birth weight - What is really important?" Indian Journal of Medical Research 130 (November): 600-8.

[20] Horta, B. L., Victora, C. G., Menezes, a M., Halpern, R., and Barros, F. C. 1997. "Low birthweight, preterm births and intrauterine growth retardation in relation to maternal smoking." Paediatric and perinatal epidemiology 11: 140-51.

[21] Abass, R. M., Hamdan, H. Z., Elhassan, E. M., Hamdan, S. Z., Ali, N. I., and Adam, I. 2014. "Zinc and copper levels in low birth weight deliveries in Medani Hospital, Sudan." BMC Research Notes 7 (1): 386.

[22] Vigeh, M., Yokoyama, K., Ramezanzadeh, F., Dahaghin, M., Fakhriazad, E., Seyedaghamiri, Z., and Araki, S. 2008. "Blood manganese concentrations and intrauterine growth restriction." Reproductive toxicology (Elmsford, N.Y.) 25 (2): 219-23.

[23] Zota, A. R., Ettinger, A. S., Bouchard, M., Amarasiriwardena, C. J., Schwartz, J., Hu, H., and Wright, R. O. 2009. "Maternal blood manganese levels and infant birth weight." Epidemiology (Cambridge, Mass.) 20 (3): 367-73.

[24] Al-Saleh, E., Nandakumaran, M., Al-Shammari, M., Al-Falah, F., and Al-Harouny, A. 2004. "Assessment of maternal-fetal status of some essential trace elements in pregnant women in late gestation: relationship with birth weight and placental weight." The Journal of Maternal-Fetal and Neonatal Medicine 16 (1): 9-14.

[25] Mora, A. M., van Wendel de Joode, B., Mergler, D., Córdoba, L., Cano, C., Quesada, R., ... Eskenazi, B. 2015. "Maternal blood and hair manganese concentrations, fetal growth, and length of gestation in the ISA cohort in Costa Rica." Environmental Research 13: 647-56.

[26] Bermúdez, L., García-Vicent, C., López, J., Torró, M. I., and Lurbe, E. 2015. "Assessment of ten trace elements in umbilical cord blood and maternal blood: association with birth weight." Journal of Translational Medicine 13 (1): 291. 
[27] ATSDR. 2012. "Toxicological profil for manganese."

[28] Hansen, S., Nieboer, E., Sandanger, T. M., Wilsgaard, T., Thomassen, Y., Veyhe, A. S., and Odland, J. Ø. 2011. "Changes in maternal blood concentrations of selected essential and toxic elements during and after pregnancy." Journal of environmental monitoring: JEM, 13(8): 2143-52.

[29] Chen, L., Ding, G., Gao, Y., Wang, P., Shi, R., Huang, H., and Tian, Y. 2014. "Manganese concentrations in maternal-infant blood and birth weight." Environmental Science and Pollution Research 21 (9): 6170-5.

[30] Eum, J.-H., Cheong, H.-K., Ha, E.-H., Ha, M., Kim, Y., Hong, Y.-C., ... Chang, N. 2014. "Maternal blood manganese level and birth weight: a MOCEH birth cohort study." Environmental Health 13 (1): 31.

[31] Xu, L., Yokoyama, K., Tian, Y., Piao, F.-Y., Kitamura, F., Kida, H., and Wang, P. 2011. "Decrease in birth weight and gestational age by arsenic among the newborn in Shanghai, China." [Nihon kōshū eisei zasshi] Japanese journal of public health 58 (2): 89-95.

[32] Johnston, J. E., Valentiner, E., Maxson, P., Miranda, M. L., and Fry, R. C. 2014. "Maternal cadmium levels during pregnancy associated with lower birth weight in infants in a North Carolina cohort." PloS one 9 (10): e109661.

[33] IkehTawari, E. P., Anetor, J. I., and M. A., C.-D. 2013. "Cadmium Level in Pregnancy, Influence on Neonatal Birth Weight and Possible Amelioration by Some Essential Trace Elements." Toxicology International, 20(1): 108-12.

[34] Sun, H., Chen, W., Wang, D., Jin, Y., Chen, X., and Xu, Y. 2014. "The effects of prenatal exposure to low-level cadmium, lead and selenium on birth outcomes." Chemosphere, 108(August 2014): 33-9.

[35] Bloom, M. S., Buck Louis, G. M., Sundaram, R., Maisog, J. M., Steuerwald, A. J., and Parsons, P. J. 2015. "Birth outcomes and background exposures to select elements, the Longitudinal Investigation of Fertility and the Environment (LIFE)." Environmental Research 138: 118-29.

[36] Dwivedi, D., Jain, M., and Jain, S. 2013. "An association between maternal lead and cadmium levels and birth weight of the babies in North Indian population.” 2013 (May): 331-6.

[37] Odland, J. O., Nieboer, E., Romanova, N., Thomassen, Y., and Lund, E. 1999. "Blood lead and cadmium and birth weight among sub-arctic and arctic populations of Norway and Russia.". Acta obstetricia et gynecologica Scandinavica 78 (10): 852-60.

[38] Gundacker, C., Fröhlich, S., Graf-Rohrmeister, K., Eibenberger, B., Jessenig, V., Gicic, D., ... Husslein, P. 2010. "Perinatal lead and mercury exposure in Austria." Science of The Total Environment 408 (23): 5744-9.
[39] Tsuzuki, S., Morimoto, N., Hosokawa, S., and Matsushita, T. 2013. "Associations of Maternal and Neonatal Serum Trace Element Concentrations with Neonatal Birth Weight." PLoS ONE 8 (9): e75627.

[40] Horvat, M., Mazej, D., Snoj Tratnik, J., Šlejkovec, Z., Jagodic, M., Fajon, V., ... Skitek, M. 2015. Monitoring kemikalij v organizmih 2011-2014.

[41] Liu, J., Oyer, R. A., Waalkes, M. P., Goyer, R. A., and Waalkes, M. P. 2008. "Toxic effects of metals". In C. D. Klaassen and J. B. Watkins (Eds.), Toxicology-The Basic Science of Poisons (pp. 931-79).

[42] Snyder, W. S., Cook, M. J., Nasset, E. S., Karkhausen, L. R., Howells, G. P., and Tipton, I. H. 1974. Report of the Task Group on Reference Man: international Commission on Radiological Protection No. 23 (1st ed., Vol. 1). Pergamon press.

[43] Barany, E., Bergdahl, I. A., Schültz, A., Skerfving, S., and Skarsson, A. 1997. "Inductively Coupled Plasma Mass Spectrometry for Direct Multi-element Analysis of Diluted Human Blood and Serum." Journal of Analytical Atomic Spectrometry 12 (9): 1005-9.

[44] US EPA. 2007. "Mercury in solids and solutions by thermal decomposition, amalgamation, and atomic absorption spectrophometry-method 7473-total Mercury." SW-846, Test Methods for Evaluating Solid Waste, Physical/Chemical Methods (February): 1-17.

[45] Li, Z., Wang, Y. a, Ledger, W., and Sullivan, E. a. 2014. "Birthweight percentiles by gestational age for births following assisted reproductive technology in Australia and New Zealand, 2002-2010." Human reproduction (Oxford, England) 29 (8): 1787-800.

[46] Takser, L., Lafond, J., Bouchard, M., St-Amour, G., and Mergler, D. 2004. "Manganese levels during pregnancy and at birth: Relation to environmental factors and smoking in a Southwest Quebec population". Environmental Research 95 (2): 119-25.

[47] Martin, J. A., Hamilton, B. E., Osterman, M. J., Curtin, S. C., and Matthews, T. J. 2015. "Births: final data for 2013.". National vital statistics reports : from the Centers for Disease Control and Prevention, National Center for Health Statistics, National Vital Statistics System 64 (1): 1-65.

[48] Yeazel, M. W., Ross, J. A., Buckley, J. D., Woods, W. G., Ruccione, K., and Robison, L. L. 1997. "High birth weight and risk of specific childhood cancers: a report from the Children's Cancer Group." The Journal of pediatrics.

[49] Wilhelm, M., Ewers, U., and Schulz, C. 2004. "Revised and new reference values for some trace elements in blood and urine for human biomonitoring in environmental medicine.". International journal of hygiene and environmental health 207 (1): 69-73.

[50] Schulz, C., Angerer, J., Ewers, U., Heudorf, U., and 
Wilhelm, M. 2009. "Revised and new reference values for environmental pollutants in urine or blood of children in Germany derived from the German environmental survey on children 2003-2006 (GerES IV)." International journal of hygiene and environmental health 212 (6): 637-47.

[51] Schulz, C., Wilhelm, M., Heudorf, U., and Kolossa-Gehring, M. 2011. "Update of the reference and HBM values derived by the German Human Biomonitoring Commission." International journal of hygiene and environmental health 215 (1): 26-35.

[52] Iyengar, G. V. 1998. "Reevaluation of the trace element content in Reference Man." Radiation Physics and Chemistry 51 (4-6): 545-60.

[53] Rodushkin, I., Ödman, F., and Branth, S. 1999. "Multielement analysis of whole blood by high resolution inductively coupled plasma mass spectrometry." Fresenius' Journal of Analytical Chemistry 364 (4): 338-46.

[54] Röllin, H. B., Kootbodien, T., Theodorou, P., and Odland, J. Ø. 2014. "Prenatal exposure to manganese in South African coastal communities." Environmental science.
Processes and impacts 16 (8): 1903-12.

[55] US EPA. 2001. Methylmercury: Reference Dose for Chronic Oral Exposure (RfD). Integrated Risk Information System.

[56] Naeem, A., Huma, Z. E., and Afridi, U. 2007. "Maternal Risk Factors Associated With Low Birth Weight." 17 (3): 223-8.

[57] Grieger, J., and Clifton, V. 2015. “A Review of the Impact of Dietary Intakes in Human Pregnancy on Infant Birthweight." Nutrients 7153-78.

[58] Leventakou, V., Roumeliotaki, T., Martinez, D., Barros, H., Brantsaeter, A.-L., Casas, M., ... Chatzi, L. 2014. "Fish intake during pregnancy, fetal growth, and gestational length in 19 European birth cohort studies." American Journal of Clinical Nutrition 99 (3): 506-16.

[59] Lee, A. Y., Kim, H., Chang, N., \& Lee, Ah Young; Kim, Hyesook; and Chang, N. 2008. "Effects of maternal dietary intake on blood heavy metal levels in antepartum and postpartum." The FASEB Journal 22 (1-Suplement): 888. 